- Notes -

\title{
A Comparative Study of Ionic Liquids and a Conventional Organic Solvent on the Extraction of Rare-earth Ions with TOPO
}

\author{
Fan YANG ${ }^{1}$, Fukiko KUBOTA ${ }^{1}$, Noriho KAMIYA ${ }^{1,2}$ and Masahiro GOTO $* 1,2$ \\ ${ }^{1}$ Department of Applied Chemistry, Graduate School of Engineering, \\ Kyushu University, Fukuoka 819-0395, Japan \\ ${ }^{2}$ Center for Future Chemistry, Kyushu University, Fukuoka 819-0395, Japan \\ (Received November 30, 2012; Accepted December 22, 2012)
}

\begin{abstract}
A comparative study of ionic liquids (ILs) and a conventional organic solvent on the extraction of rare-earth ions from a nitrate-contained solution with TOPO has been investigated. A slope analysis was carried out to determine the extraction mechanism, and it was found that more TOPO molecules and the ionic constituents of the ILs have taken part in the extraction reaction in the ILs-based TOPO extraction systems. The numbers of TOPO molecules coordinated to the metal ion in the extracted complexes were 6 and 4 in the $\left[\mathrm{C}_{4} \mathrm{mim}\right]$ and $\left[\mathrm{C}_{8} \mathrm{mim}\right]\left[\mathrm{Tf}_{2} \mathrm{~N}\right]$ systems, although 3 TOPO molecules were needed in the $n$-dodecane system. Higher extraction efficiency was obtained in the extraction system in which the higher coordinating number of TOPO was shown. The extraction ability of $\left[\mathrm{C}_{8} \mathrm{mim}\right]\left[\mathrm{Tf}_{2} \mathrm{~N}\right]$-based TOPO depends significantly on the ionic constituents of the ILs in the extracting phase, but depends only slightly on the anionic nitrate ion from the aqueous phase, and $\left[\mathrm{C}_{4} \mathrm{mim}\right]\left[\mathrm{Tf}_{2} \mathrm{~N}\right]$-based TOPO is not dependent on the nitrate ion.
\end{abstract}

\section{Introduction}

Recently, replacement of conventional organic solvents with ionic liquids (ILs) has been considered as a new trend in liquid-liquid extraction of rare-earth ions [1]. ILs are novel types of solvents which are cation/anion salts in the liquid state at room temperature, and they are already known as "green" solvents due to their unique properties such as negligible vapor pressure, non-flammability and they are less hazardous than conventional solvent [2]. ILs have been also called "designer solvents" because the physicochemical properties of the ILs are tunable in order to be suitable for their applications [3]. For 
example, $\left[\mathrm{C}_{\mathrm{n}} \operatorname{mim}\right]\left[\mathrm{Tf}_{2} \mathrm{~N}\right]$ (1-alkyl-3-methylimidazolium bis(trifluoromethylsulfonyl) imide)) is a typical hydrophobic IL, which can solubilize a variety of inorganic, organic and polymeric materials by adjusting the 1-alkyl chain in the 3-methylimidazolium cation [4], so that $\left[\mathrm{C}_{n} \operatorname{mim}\right]\left[\mathrm{Tf}_{2} \mathrm{~N}\right]$ can be used for liquid-liquid extraction and separation of metal ions.

Over the last decade, studies of ILs in liquid-liquid extraction and separation of rare-earth ions have been carried out, and a number of effective extraction systems have been reported, such as CMPO (octyl(phenyl)- $N, N$-diisobutylcarbamoylmethyl phosphine oxide) in $\left[\mathrm{Bmim}^{2}\right]\left[\mathrm{PF}_{6}\right]$ (1-butyl-3-methylimidazolium hexafluorophosphate) or $[\mathrm{Bmim}]\left[\mathrm{Tf}_{2} \mathrm{~N}\right]$ (1-butyl-3-methylimidazolium bis[(trifluoromethyl)sulfonyl]imide) [5], DODGAA ( $N, N$-dioctyldiglycol amic acid) in $\left[\mathrm{C}_{\mathrm{n}} \operatorname{mim}\right]\left[\mathrm{Tf}_{2} \mathrm{~N}\right](\mathrm{n}=2,4,8)[6,7]$, Htta (2-thenoyltrifluoroacetone) in $\left[\mathrm{C}_{4} \operatorname{mim}\right]\left[\mathrm{Tf}_{2} \mathrm{~N}\right] \quad$ [8], PC-88A (2-Ethylhexyl phosphonic acid mono-2-ethylhexyl ester) in [ $\left.\mathrm{C}_{\mathrm{n}} \mathrm{mim}\right][\mathrm{TFSI}](\mathrm{n}=2,4,8,12)$ [9], and TODGA $\left(N, N, N^{\prime}, N^{\prime}\right.$-tetra(n-octyl) diglycolamide) in $\left[\mathrm{C}_{\mathrm{n}} \operatorname{mim}\right]\left[\mathrm{Tf}_{2} \mathrm{~N}\right](\mathrm{n}=2,4,6)[10]$. Based on these works, IL-based extraction processes for rare-earth ions should be continued on a broad front and vigorously developing in the future.

In this work, a neutral extractant TOPO (Tri- $n$-octylphosphine oxide), which was recently used with $\left[\mathrm{C}_{\mathrm{n}} \operatorname{mim}\right]\left[\mathrm{Tf}_{2} \mathrm{~N}\right]$ [11], was employed for the extraction of rare-earth ions from nitrate medium to obtain basic information for extending the application of ILs. The objectives of this study were to investigate the difference in the extraction behavior of metal ions with TOPO in $\left[\mathrm{C}_{n} \operatorname{mim}\right]\left[\mathrm{Tf}_{2} \mathrm{~N}\right]$ and in $n$-dodecane, and explain the difference by clarifying the extraction mechanisms.

\section{Experimental}

\subsection{Reagents}

The extractant TOPO was purchased from

Wako Pure Chemical Industries, Ltd. Hydrophobic ionic liquids used as diluents, $\left[\mathrm{C}_{\mathrm{n}} \operatorname{mim}\right]\left[\mathrm{Tf}_{2} \mathrm{~N}\right](\mathrm{n}=2: 1$-Ethyl-, $\mathrm{n}=4:$ 1-Butyl-, and $\mathrm{n}=8$ : 1-Octyl- 3-methylimidazolium bis (trifluoromethyl sulfonyl) imide) (lot No. and assay: I01825.1.2 (> $99 \%)$, F00101.5 (> $99 \%)$

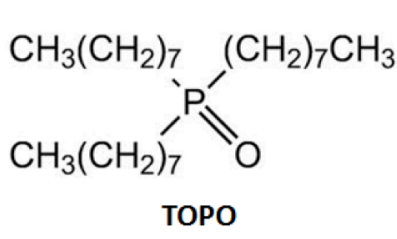

Figure 1. Molecular structures of TOPO and the ionic liquids used in this study. and 100327.1 (> $99 \%$ ), respectively), were supplied by Ionic Liquids Technologies GmbH Inc. $n$-Dodecane and ammonium nitrate $\left(\mathrm{NH}_{4} \mathrm{NO}_{3}\right)$ were provided by KISHIDA CHEMICAL Co., Ltd. (Osaka, Japan). The molecular structures of the extractant and the ionic liquids are shown in Figure 1.

\subsection{Procedure for liquid-liquid extraction}

The feed aqueous solutions containing $0.1 \mathrm{mM}$ rare-earth metal ions were prepared by dissolving their nitrate salts in aqueous solutions containing $\mathrm{NH}_{4} \mathrm{NO}_{3}$. The extracting phases were prepared by dissolving TOPO in an ionic liquid, $\left[\mathrm{C}_{\mathrm{n}} \operatorname{mim}\right]\left[\mathrm{Tf}_{2} \mathrm{~N}\right](\mathrm{n}=2,4,8)$ or $n$-dodecane. 
Equal volumes of the aqueous and IL phases were transferred to a sealed polypropylene-test tube. The mixture was vigorously shaken by a vortex mixer for 10 minutes to attain equilibrium and then gently shaken in a thermostatic bath $(298 \mathrm{~K})$ for 12 hours to achieve constant temperature. The mixtures were centrifuged for $3 \mathrm{~min}(5000 \mathrm{rpm}, 298 \mathrm{~K})$ and the concentrations of the metal ions in the aqueous phases were determined using an ICP-atomic emission spectrometer (Perkin Elmer Co., Optima 5300) after phase separation. Then the extraction degree, $E[-]$, and distribution ratio $(D)$ were calculated by the following equations:

$$
\begin{aligned}
& E=\left(\left([\mathrm{M}]_{\mathrm{aq}, 0}-[\mathrm{M}]_{\mathrm{aq}}\right) /[\mathrm{M}]_{\mathrm{aq}, 0}\right) \\
& D=\left(\left([\mathrm{M}]_{\mathrm{aq}, 0}-[\mathrm{M}]_{\mathrm{aq}}\right) /[\mathrm{M}]_{\mathrm{aq}}\right)
\end{aligned}
$$

where $[\mathrm{M}]$ represents the rare earth metal concentration and the subscript aq denotes the aqueous phase, and 0 is the initial state.

\section{Results and Discussion}

\subsection{Solubility and extraction ability of TOPO in $\left[\mathrm{C}_{n} \mathrm{mim}\right]\left[\mathrm{Tf}_{2} \mathrm{~N}\right]$ and $n$-dodecane}

As previously reported, neutral extractants such as dicyclohexano-18-crown-6 (DC18C6) and CMPO are readily soluble in imidazolium-based ILs, however acidic extractants such as PC-88A and neodecanoic acid (Versatic 10) showed poor solubility in the ILs [7]. The solubility of extractants in ILs greatly affects the extraction performance, therefore the solubility of TOPO in $\left[\mathrm{C}_{n} \operatorname{mim}\right]\left[\mathrm{Tf}_{2} \mathrm{~N}\right]$ was examined. The neutral extractant TOPO $(30 \mathrm{mM})$ was solubilized in the $\left[\mathrm{C}_{\mathrm{n}} \mathrm{mim}\right]\left[\mathrm{Tf}_{2} \mathrm{~N}\right]$ for which the carbon number $\mathrm{n}$ for the 1-alkyl substituent in the imidazolium cation was 4 or greater, although it was slightly soluble in $\left[\mathrm{C}_{2} \mathrm{mim}\right]\left[\mathrm{Tf}_{2} \mathrm{~N}\right]$ unlike DC18C6 due to the bulky alkyl substituents in the TOPO molecule. Then the extraction behavior was examined mainly in the ILs, $\left[\mathrm{C}_{4} \mathrm{mim}\right]$ and $\left[\mathrm{C}_{8} \mathrm{mim}\right]\left[\mathrm{Tf}_{2} \mathrm{~N}\right]$.

First, compared to the $n$-dodecane system, the extraction ability of TOPO in the $\left[\mathrm{C}_{n} \operatorname{mim}\right]\left[\mathrm{Tf}_{2} \mathrm{~N}\right]$ system for rare earth ions $(\mathrm{Nd}, \mathrm{Eu}, \mathrm{Dy}$ and $\mathrm{Nd})$ was evaluated. As can be seen in Figure 2, the rare earth ions are hardly extracted at all with TOPO in $n$-dodecane from the feed aqueous phase containing $0.1 \mathrm{M}$ nitrate. On the other hand, the IL extraction systems have significantly improved the extraction efficiency. The ILs having a shorter 1-substituted alkyl chain in the imidazolium cation gave higher extraction ability. As described later, a rare earth ion is extracted via the exchange of the metal ion and the imidazolium cations of the IL, and the ILs having a more hydrophilic imidazolium cation showed a higher extraction performance. The extraction of the rare earth ions was enhanced by the addition of $20 \%\left[\mathrm{C}_{2} \mathrm{mim}\right]\left[\mathrm{Tf}_{2} \mathrm{~N}\right]$ to $\left[\mathrm{C}_{4} \mathrm{mim}\right]\left[\mathrm{Tf}_{2} \mathrm{~N}\right]$ compared to that for the pure $\left[\mathrm{C}_{4} \mathrm{mim}\right]\left[\mathrm{Tf}_{2} \mathrm{~N}\right]$ as shown in Figure 2, because the more hydrophilic $\left[\mathrm{C}_{2} \mathrm{mim}\right]^{+}$was considered to be released to the aqueous phase more easily than $\left[\mathrm{C}_{4} \mathrm{mim}\right]^{+}$. 


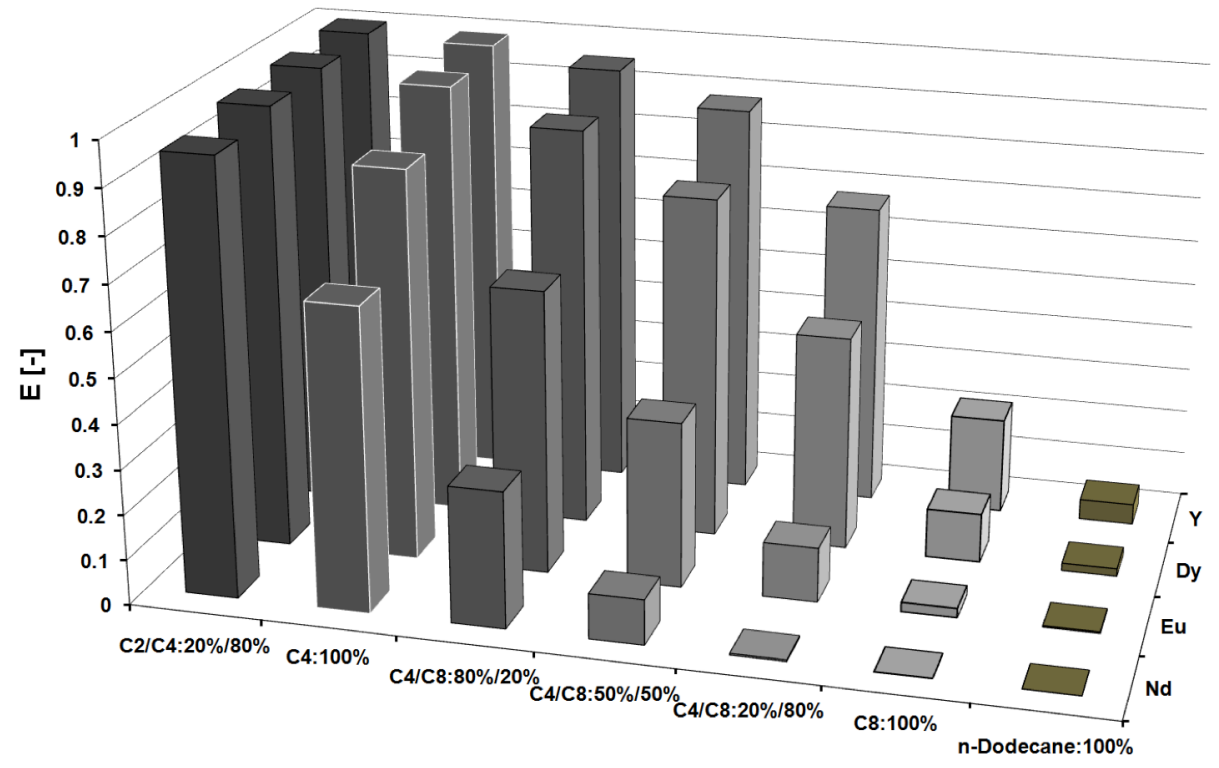

Figure 2. The extraction efficiency of rare-earth ions with TOPO in the $\left[\mathrm{C}_{\mathrm{n}} \operatorname{mim}\right]\left[\mathrm{Tf} \mathrm{f}_{2} \mathrm{~N}\right]$ system or in $n$-dodecane. Concentration of metal ion and nitrate: $0.1 \mathrm{mM}$ and $0.1 \mathrm{M}$, respectively. Concentration of TOPO: $30 \mathrm{mM}$

First, compared to the $n$-dodecane system, the extraction ability of TOPO in the $\left[\mathrm{C}_{n} \operatorname{mim}\right]\left[\mathrm{Tf}_{2} \mathrm{~N}\right]$ system for rare earth ions ( $\mathrm{Nd}, \mathrm{Eu}$, Dy and $\mathrm{Nd}$ ) was evaluated. As can be seen in Figure 2, the rare earth ions are hardly extracted at all with TOPO in $n$-dodecane from the feed aqueous phase containing $0.1 \mathrm{M}$ nitrate. On the other hand, the IL extraction systems have significantly improved the extraction efficiency. The ILs having a shorter 1-substituted alkyl chain in the imidazolium cation gave higher extraction ability. As described later, a rare earth ion is extracted via the exchange of the metal ion and the imidazolium cations of the IL, and the ILs having a more hydrophilic imidazolium cation showed a higher extraction performance. The extraction of the rare earth ions was enhanced by the addition of $20 \%\left[\mathrm{C}_{2} \mathrm{mim}\right]\left[\mathrm{Tf}_{2} \mathrm{~N}\right]$ to $\left[\mathrm{C}_{4} \operatorname{mim}\right]\left[\mathrm{Tf}_{2} \mathrm{~N}\right]$ compared to that for the pure $\left[\mathrm{C}_{4} \mathrm{mim}\right]\left[\mathrm{Tf}_{2} \mathrm{~N}\right]$ as shown in Figure 2, because the more hydrophilic $\left[\mathrm{C}_{2} \mathrm{mim}\right]^{+}$was considered to be released to the aqueous phase more easily than $\left[\mathrm{C}_{4} \mathrm{mim}\right]^{+}$.

\subsection{Effect of TOPO and nitrate concentrations on the extraction efficiency}

TOPO is a neutral organophosphorous extractant, and it can extract rare-earth ions but they must be accompanied by some anionic species as the counter anions from the aqueous phase in a conventional organic solvent system, so that the extraction efficiency is influenced by the TOPO and nitrate concentrations. Figures 3 A-1, 2 and 3 show the effect of TOPO concentration on the extraction efficiency of the rare earth ions from an aqueous phase containing $0.1 \mathrm{M}$ nitrate in $n$-dodecane, $\left[\mathrm{C}_{4} \operatorname{mim}\right]\left[\mathrm{Tf}_{2} \mathrm{~N}\right]$ and $\left[\mathrm{C}_{8} \operatorname{mim}\right]\left[\mathrm{Tf}_{2} \mathrm{~N}\right]$ systems, respectively. In the $n$-dodecane system, the extraction efficiency was significantly affected by the nitrate concentration as shown in Figure 3 B-1, therefore, under the present nitrate concentration, a significant effect of TOPO concentration was not observed. In contrast, in the 
$\left[\mathrm{C}_{4} \mathrm{mim}\right]\left[\mathrm{Tf}_{2} \mathrm{~N}\right]$ system, the extraction efficiency was greatly enhanced by an increase in the TOPO concentration. In the $\left[\mathrm{C}_{4} \mathrm{mim}\right]\left[\mathrm{Tf}_{2} \mathrm{~N}\right]$ system, the extraction efficiency does not depend on the nitrate concentration in the aqueous phase as shown in Figure $3 \mathrm{~B}-2$. For the $\left[\mathrm{C}_{8} \operatorname{mim}\right]\left[\mathrm{Tf}_{2} \mathrm{~N}\right]$ system, the extraction efficiency was dependent on the TOPO and nitrate concentrations (Figures 3 A-3 and B-3).
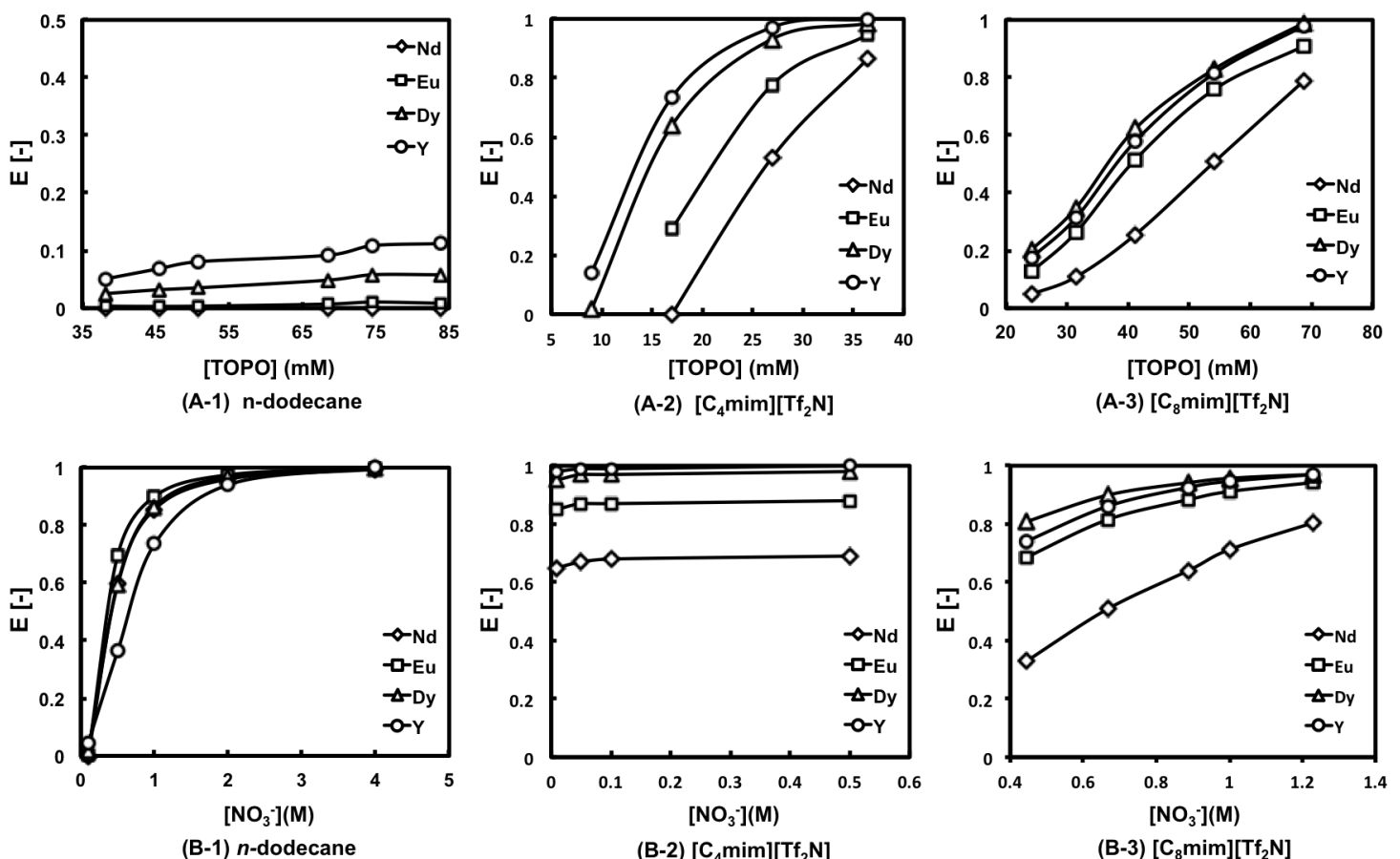

Figure 3. The effect of TOPO and nitrate concentrations on extraction efficiency in $\left[\mathrm{C}_{\mathrm{n}} \mathrm{mim}\right]\left[\mathrm{Tf}_{2} \mathrm{~N}\right]$ and in $n$-dodecane. Nitrate concentration: $0.1 \mathrm{mM}$ for A-1, 2 and 3 . TOPO concentration: $30 \mathrm{mM}$ for B-1, 2 and 3.

\subsection{Slope analysis}

In order to clarify the extraction mechanism of rare earth ions with TOPO in the $\left[\mathrm{C}_{\mathrm{n}} \operatorname{mim}\right]\left[\mathrm{Tf}_{2} \mathrm{~N}\right]$ systems and in the $n$-dodecane system, slope analysis was performed as a function of the equilibrium concentration of TOPO in the extracting phase and the nitrate concentration in the aqueous phase.

According to the logarithmic plots of $D$ against the TOPO concentration (Figure 4 A-1) and nitrate ion concentration (data not shown), the equilibrium equation in the $n$-dodecane system is represented by Eq.(3) as has been already reported [12].

$$
\mathrm{M}^{3+}{ }_{\text {aq }}+3 \mathrm{TOPO}_{\text {org }}+3 \mathrm{NO}_{3}{ }_{\text {aq }}^{-} \rightleftharpoons \mathrm{M} \cdot 3 \mathrm{TOPO} \cdot 3 \mathrm{NO}_{3, \mathrm{org}}
$$

In the IL extraction system, it seemed that more TOPO molecules were involved in the extraction reaction than in the $n$-dodecane system. As shown in Figures 4 A-2 and A-3, the linear dependencies with slopes of 6 and 4 were obtained for $\left[\mathrm{C}_{4} \mathrm{mim}\right]$ and $\left[\mathrm{C}_{8} \mathrm{mim}\right]\left[\mathrm{Tf}_{2} \mathrm{~N}\right]$, respectively, and this indicates that 6 TOPO molecules and 4 TOPO molecules coordinate to one metal ion in the extracted species in each 
system. The slopes of the linear dependency of $\log D$ against the nitrate concentration were 2 for $\left[\mathrm{C}_{8} \mathrm{mim}\right]$, as shown in Figure $4 \mathrm{~B}-1$, while for $\left[\mathrm{C}_{4} \mathrm{mim}\right]$, the extraction ability was not affected by the nitrate concentration as described above. Thus the extraction reactions are represented by Eqs.(4) and (5) for respective IL systems.

$$
\begin{aligned}
& \mathrm{M}^{3+}{ }_{\text {aq }}+6 \mathrm{TOPO}_{\mathrm{IL}}+3 \mathrm{C}_{4} \mathrm{mim}^{+} \cdot \mathrm{Tf}_{2} \mathrm{~N}_{\mathrm{IL}}^{-} \rightleftharpoons \mathrm{M} \cdot 6 \mathrm{TOPO} \cdot 3 \mathrm{Tf}_{2} \mathrm{~N}_{\mathrm{IL}}+3 \mathrm{C}_{4} \mathrm{mim}^{+}{ }_{\mathrm{aq}} \\
& \mathrm{M}^{3+}{ }_{\text {aq }}+4 \mathrm{TOPO}_{\mathrm{IL}}+2 \mathrm{NO}_{3}{ }_{\text {aq }}^{-}+\mathrm{C}_{8} \mathrm{mim}^{+} \cdot \mathrm{Tf}_{2} \mathrm{~N}_{\mathrm{IL}}^{-} \rightleftharpoons \mathrm{M} \cdot 4 \mathrm{TOPO} \cdot 2 \mathrm{NO}_{3} \cdot \mathrm{Tf}_{2} \mathrm{~N}_{\mathrm{IL}}+\mathrm{C}_{8} \mathrm{mim}^{+}{ }_{\text {aq }}
\end{aligned}
$$
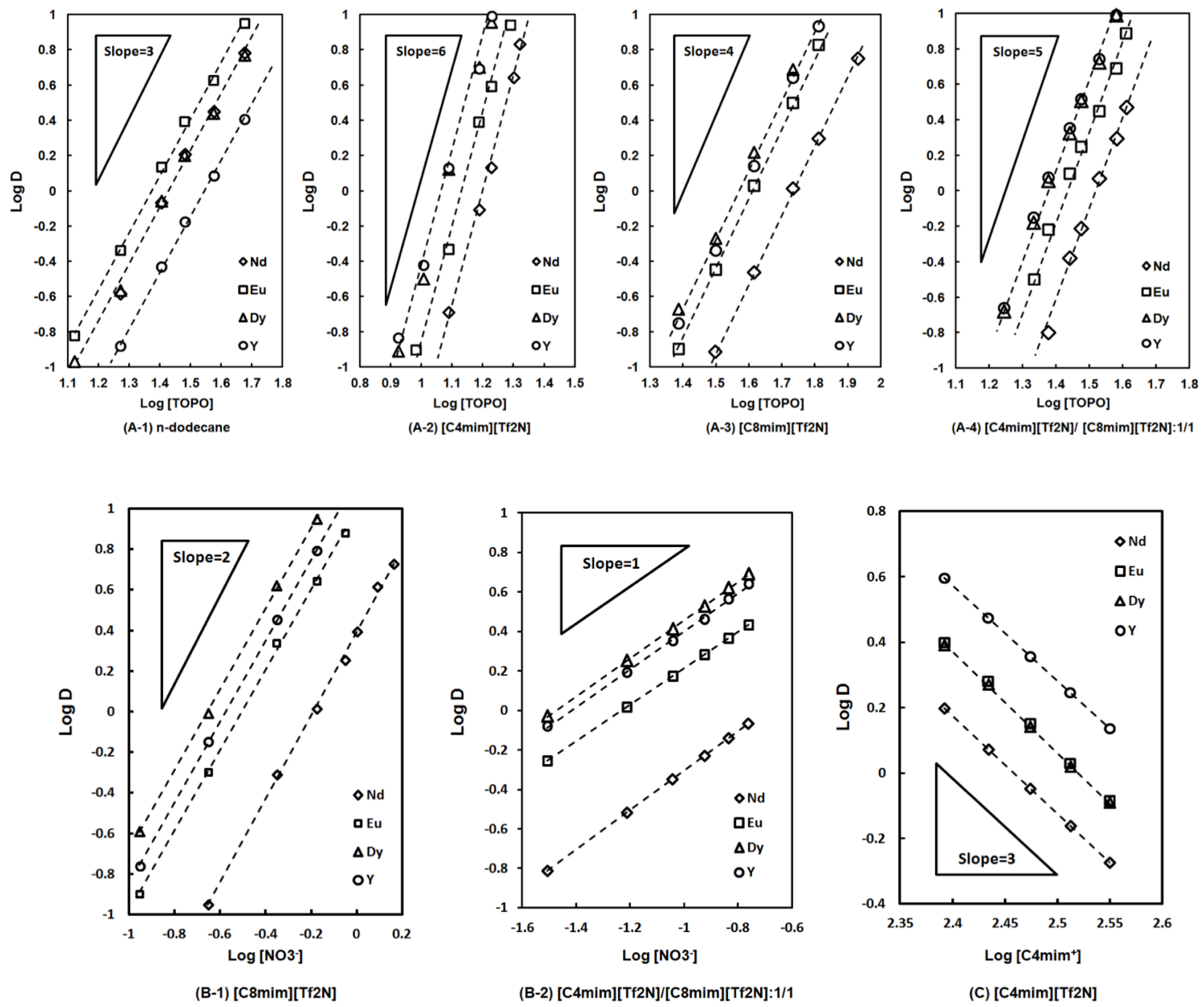

Figure 4. Slope analysis of the extraction of rare earth ions with TOPO in the $\left[\mathrm{C}_{\mathrm{n}} \operatorname{mim}\right]\left[\mathrm{Tf}_{2} \mathrm{~N}\right]$ or n-dodecane systems. Nitrate concentration: $0.5 \mathrm{M}$ for A-1, $0.1 \mathrm{M}$ for A-2 4 and C. TOPO concentration: $30 \mathrm{mM}$ for $\mathrm{B}-1,2$ and $\mathrm{C}$.

The extraction equation was confirmed by slope analysis in the mixture of equal volumes of [ $\left.\mathrm{C}_{4} \mathrm{mim}\right]$ and $\left[\mathrm{C}_{8} \mathrm{mim}\right]$. A linear relationship with a slope 5 for the TOPO concentration (Figure 4 A-4) and 1 for the nitrate concentration were found (Figure $4 \mathrm{~B}-2$ ), which are equal to the average values in the $\left[\mathrm{C}_{4} \mathrm{mim}\right]$ and $\left[\mathrm{C}_{8} \mathrm{mim}\right]$ systems. Furthermore, the effect of the $\left[\mathrm{C}_{4} \mathrm{mim}^{+}\right]$concentration in the aqueous phase on the extraction in the $\left[\mathrm{C}_{8} \mathrm{mim}\right]\left[\mathrm{Tf}_{2} \mathrm{~N}\right]$-based TOPO system was examined by adding 1-butyl-3-methylimidazolium chloride, $\left[\mathrm{C}_{4} \mathrm{mim}\right][\mathrm{Cl}]$, to the aqueous phase as a source of $\left[\mathrm{C}_{4} \mathrm{mim}^{+}\right]$. A decrease in $D$ 
inversely with the cube of the $\left[\mathrm{C}_{4} \mathrm{mim}^{+}\right]$concentration was observed as shown in Figure $4 \mathrm{C}$, and this result supports the extraction mechanism expressed by Eq.(4). $\left[\mathrm{C}_{\mathrm{n}} \operatorname{mim}\right]\left[\mathrm{Tf}_{2} \mathrm{~N}\right]$ is compatible with such "large ionic-complexes" of $\mathrm{M}^{3+}$ with TOPO and this may be due to the characteristics of ILs such as polarity and ionicity. However, this phenomenon does not appeared in the other IL-based neutral extractant systems such as CMPO [5], perhaps because the TOPO molecule is smaller and the structure is more simple than that of CMPO, which has two coordination sites $\mathrm{P}=\mathrm{O}$ and $\mathrm{C}=\mathrm{O}$ whereas TOPO has only one site $\mathrm{P}=\mathrm{O}$.

As shown in Figure 4, the selectivity of TOPO for the rare earth ions in the IL systems was different from that in the $n$-dodecane system, the order being as follows:

1) $\mathrm{Eu}>\mathrm{Dy}, \mathrm{Nd}>\mathrm{Y}$ in the $n$-dodecane system. (Figure $4 \mathrm{~A}-1$ ).

2) $\mathrm{Y}>$ Dy or Dy $>\mathrm{Y}>\mathrm{Eu}>\mathrm{Nd}$ in the $\left[\mathrm{C}_{\mathrm{n}} \operatorname{mim}\right]\left[\mathrm{Tf}_{2} \mathrm{~N}\right](\mathrm{n}=4$ and 8$)$ systems. (Figures $4 \mathrm{~A}-2$ and 3 ).

The difference in the selectivity is considered to be due to the difference in the coordination sphere in the organic solvent and the ILs, where the anions of the ILs also coordinate to the metal ions as the counter-anions of the ionic complex of $\mathrm{M}^{3+}$ with TOPO.

In summary, TOPO is considered to play a dominant role in the IL-based extraction system because more TOPO molecules were allowed to participate in the extraction reaction, while in a conventional organic solvent, the extraction ability was highly dependent on the nitrate ion concentration in the aqueous phase.

\section{Conclusion}

The extraction behavior of rare earth ions with trioctyl phosphine oxide (TOPO) in ionic liquids (ILs) was studied. Based on the results obtained, it was found that IL-based extraction systems showed higher extraction ability than that using a conventional organic solvent, $n$-dodecane. Comparing the results of slope analysis in the two systems, it was shown that more TOPO molecules were involved in the extracted complex in the ionic liquid systems than that in the $n$-dodecane system, and the ionic species of the ILs also took part in the extraction reaction in the IL systems.

\section{References}

1) X.Q. Sun, H.M. Luo, S. Dai, Chem. Rev., 112 (4), 2011(2012).

2) P. Wassercheid, W. Keim, Angew. Chem. Int. Ed., 39, 3773(2000).

3) J. Ranke, S. Stolte, R. Störmann, J. Arning, B. Jastorff, Chem. Rev.,107, 2183(2007).

4) M. G. Freire, P. J. Carvalho, R. L. Gardas, I. M. Marrucho, Lus M. N. B. F. Santos, Joo A. P. Coutinho, J. Phys. Chem. B,112, 1604 (2008).

5) K. Nakashima, F. Kubota, T. Maruyama, M. Goto, Ind. Eng. Chem. Res., 44, 4368(2005).

6) F. Yang, Y. Baba, F. Kubota, N. Kamiya, M. Goto, Solvent Extr. Res. Dev., Jpn., 19, 69 (2012).

7) F.Kubota, Y. Shimobori, Y. Baba, Y. Koyanagi, K. Shimojo, N. Kamiya, M. Goto, Solvent Extr. Res. Dev., Jpn., 44, 307(2011). 
8) P.M. Jensen, J. Neuefeind, V.J. Beitz, S. Skanthakumar, L. Soderholm, J. Am. Chem. Soc., 125, 15466 (2003).

9) F. Kubota, Y. Koyanagi, K. Nakashima, K. Shimojo, N. Kamiya, M. Goto, Solvent Extr. Res. Dev., Jpn., 15, 81(2008).

10) K. Shimojo, K. Kurahashi, H. Naganawa, Dalton Trans., 37, 5083 (2008).

11) F. Kubota, Y. Shimobori, Y. Koyanagi, K. Nakashima, K. Shimojo, N. Kamiya, M. Goto, Solvent Extr. Res. Dev., Jpn., 16, 151(2009).

12) Y.A. El-Nadi, Hydrometallurgy, 119, 23 (2012). 